\title{
Serum vitamin A level in bronchiolitis with respiratory syncytial virus infection
}

\author{
Professor Chen Hui-Zhong \\ Department of Pediatrics, The Affiliated Children's Hospital \\ of the Capital Institute of Pediatrics,Beijing,P.R.China
}

\begin{abstract}
To explore the relation between vitamin A and lower respiratory infection caused by respiratory syncytial virus (RSV) confirmed by antigen test and (or) viral culture, we studied 46 cases of bronchiolitis with RSV infection and 26 controls. Serum vitamin A level of 46 patients during acute illness (day 0,7), convalescence (day 15) and of control infants were measured. Serum vitamin A level between mild and severe patients (Lowell's criterion) was also compared. The results showed that serum vitamin A level at acute stage, convalescence of illness and controls was $0.94 \pm 0.15 \mu \mathrm{mol} / \mathrm{L}, 1.38 \pm 0.30 \mu \mathrm{mol} / \mathrm{L}$ and $1.47 \pm 0.30 \mu \mathrm{mol} / \mathrm{L}$, respectively. Twelve severe cases out of $20(60 \%)$ had serum vitamin A level below the mean minus $2 \mathrm{SD}$ of the value of control infants, whereas only 5 mild patients out of $26(19.2 \%)$ had vitamin A level below such value $\left(\chi^{2}=8.06, \mathrm{p}<0.01\right)$. The results of this study indicate that serum concentration of vitamin A decreases at acute stage of illness and is spontaneously recovered at convalescence. The degree of the decrease in serum vitamin A at acute stage of bronchiolitis was associated with the severity of illness.
\end{abstract}

Key words : Respiratory syncytial virus infections Vitamin A Bronchiolitis 